\title{
THE MOBILIZATION OF YOUTH POLITICAL PROTEST AND RUSSIAN VIDEO BLOGGERS: COGNITIVE MAPPING RESULTS
}

\author{
Anna V. Shentyakova ${ }^{1}$ (a) \& Nikolai V. Grishin' ${ }^{2}$ (a)
}

(a) St. Petersburg State University. Saint Petersburg, Russia

\begin{abstract}
The paper presents the results of using the cognitive mapping method to analyze the messages from video bloggers which were popular among Russian youth and covered protest actions in Russia in 2019-2020. The cognitive mapping method has not previously been used to interpret the information messages of representatives of the protest movement in modern Russia. The objective of the study is to identify the value systems, priorities, individual logical chains of opinion leaders in the Russian language segment of YouTube video hosting. The research sample was based on a two-step model, including the selection of 20 video bloggers who are considered to be the most popular among Russian protest youth as well as the selection of information materials for further analysis. For each leader of public opinion, several cognitive maps were built regarding the coverage of protest actions in 3 cases (the protests in Yekaterinburg in 2019, in Moscow after the Moscow City Duma elections in 2019 and in Khabarovsk in 2020). The cognitive mapping method made it possible to analyze the perception and interpretation of the protest actions taken by public opinion leaders who are opposed to the ruling party. The results of cognitive mapping reveal the value systems of the interpreters of political events who are popular among young people. The system of values, expressed in the interpretation of protest actions, presupposes the dominance of liberal guidelines, ideas of the rule of law and civil society.
\end{abstract}

\section{Keywords}

political protest; video blogging; online mobilization; online political participation; Russian youth; political mobilization; mobilizing youth; cognitive mapping; opposition; opposition blogs

\section{(c) (1)}

This work is licensed under a Creative Commons «Attribution» 4.0 International License

1 Email: anna_pedagog[at]mail.ru

2 Email: nvgrishin[at]mail.ru 


\section{МОБИЛИЗАЦИЯ ПОЛИТИЧЕСКОГО ПРОТЕСТА МОЛОДЕЖИ И РОССИЙСКИЕ ВИДЕОБЛОГЕРЫ: РЕЗУЛЬТАТЫ КОГНИТИВНОГО КАРТИРОВАНИЯ}

\section{Шентякова Анна Владимировна ${ }^{1}$ (a), Гришин Николай Владимирович ${ }^{2}$ (a)}

(а) Санкт-Петербургский государственный университет. Санкт-Петербург, Россия

\section{Аннотация}

В статье представлены результаты применения метода когнитивного картирования для анализа сообщений популярных среди российской молодежи видеоблогеров о протестных акциях в России в 2019-2020 гг. Метод когнитивного картирования ранее не использовался для интерпретации информационных сообщений представителей протестного движения в современной России. Задачей исследования было выявление ценностных установок, приоритетов, индивидуальных логических цепочек лидеров общественного мнения в русскоязычном сегменте видеохостинга YouTube. Выборка исследования строилась по 2 ступенчатой модели, включающей отбор 20 наиболее популярных у российской протестной молодежи видеоблогеров и отбор информационных материалов для последующего анализа. Для каждого лидера общественного мнения было построено несколько когнитивных карт относительно освещения протестных акций по 3 кейсам (протесты в Екатеринбурге в 2019 г., в Москве после выборов в Мосгордуму в 2019 г., в Хабаровске в 2020 г.). Метод когнитивного картирования позволил проанализировать восприятие и интерпретацию лидерами общественного мнения, которые оппозиционно настроены по отношению к власти, акций протеста. Результаты когнитивного картирования раскрывают ценностную систему популярных среди молодежи интерпретаторов политических событий. Система ценностей, выраженная в интерпретации протестных акций, предполагает доминирование либеральных ориентиров, идей правового государства и гражданского общества.

\section{Ключевые слова}

политический протест; видеоблогинг; онлайн мобилизация; политическое онлайн участие; российская молодежь; политическая мобилизация; мобилизация молодежи; когнитивное картирование; оппозиция; оппозиционные блоги

Это произведение доступно по лицензии Creative Commons «Attribution» («Атрибуция») 4.0 Bceмирная

1 Email: anna_pedagog[at]mail.ru

2 Email: nvgrishin[at]mail.ru 


\section{ВВЕДЕНИЕ}

Влияние видеоблогеров на молодежь современной России находится в центре внимания как исследователей, так и практиков политического управления. Значительный приток молодежи в российское оппозиционное движение был признан в 2017 г. (Лагутин \& Шентякова, 2018), в частности, после выхода видеоролика «Он вам не Димон» (Морозова, 2018). В специфических условиях существования традиционных СМИ в современной России и продолжающегося падения их популярности можно ожидать усиление значимости интернетблогеров для процесса формирования политического сознания и поведения российской молодежи (Соколов \& Палагичева, 2020; Гришин \& Линдерс, 2020).

Научная проблема, решению которой способствует данная статья, заключается в отсутствии знаний об особенностях мобилизующего воздействия российских видеоблогеров оппозиционной направленности на молодежную аудиторию. В исследованиях политического видеоблогинга в России фокус внимания обычно сосредоточен на вопросах политической направленности блогеров, степени их радикальности или умеренности (Роменков, 2008), речевых особенностей и т. д. (Шарапов, 2017). За пределом внимания остаются методы и формы мобилизующего воздействия видеологеров, в частности, способы распространения ценностных установок. Между тем, анализ сообщений, транслируемых популярными видеоблогерами, способен расширить наши знания о потенциале и особенностях политической мобилизации посредством современных информационных стедств.

Целью данной статьи является выявление ценностных и мобилизирующих компонентов в информационных обзорах наиболее популярных российских молодежных видеоблогеров, способных оказывать влияние на ценностные установки, смыслы и взгляды молодежной части аудитории при освещении и интепретации политических протестов.

Теоретическим ориентиром исследования выступает теория «двухступенчатой коммуникации» в ее адаптации к современной эпохе использования новых информационных технологий. Применяя данную теорию, мы следовали апробированному в ее рамках подходу, в соответствие с которым популярные блогеры могут быть рассмотрены как лидеры общественного мнения, оказывающие влияние на аудиторию в специфических условиях сетевого общества (Karlsen, 2015). Рассмотрение блогеров как лидеров общественного мнения соответствует исследуемой в данной статье ситуации, 
поскольку выбранные для анализа блогеры фигурируют в числе лиц, признанных наиболее популярными медийными персонами у молодежной аудитории.

\section{МЕТОДОЛОГИЯ ИССЛЕДОВАНИЯ}

Когнитивное картирование - один из качественных методов анализа текстовых данных, который позволяет измерить психологические параметры политических лидеров или других политических субъектов. Данный метод был разработан в рамках когнитивной психологии для поиска в структуре мышления отдельного человека устойчивых конструкций познания и понимания окружающей реальности (Olazabal et al, 2018). Операционный код традиционно определяется как система когнитивных конструкций, которая используется политическим актором при анализе им конкретных политических ситуаций относительно постоянно, что и делает возможным ее выявление (Gray et al, 2015).

Процедура когнитивного картирования сочетает в себе два компонента:

1) психологический элемент направлен на поиск категорий и базовых смысловых понятий;

2) статистическая составляющая предполагает подсчет связей между категориями и анализ связей между ними. «Содержит три последовательные процедуры:

а) определение суждений, терминов, устойчивых выражений, которыми оперирует политический деятель;

b) указание существующих между высказываниями причинноследственных связей;

с) оценку значимости, устойчивости и «плотности» причинноследственных связей между тематическими высказываниями» (Попова, 2009).

С середины XX века разрабатываются и совершенствуются методики проведения и анализа индивидуальных когнитивных карт (Авдеева \& Коврига, 2014). Одним из первых разработчиков в этой области считается Н. Лейтес, который предложил термин «операционный код» в работах «Операционный код политбюро» и «Исследование большевизма» в начале 50-х годов (Leites, 1951). Предложенная им методика активно разрабатывалась и развивалась Р. Абельсоном 
(Abelson, 1979), Р. Аксельродом (Axelrod, 1976), М. Бонэм, Д. Херадсвейт, М. Шапиро и др. Р. Аксельрод предложил рассматривать когнитивную карту как «совокупность утверждений, связанных между собой каузальными связями. Посредством подобных каузальных связей выстраиваются цепочки последовательных утверждений, которые и формируют "картину мира" лица, принимающего решения по определенному вопросу». По мнению Аксельрода Р. создание подобной когнитивной карты, позволяет прогнозировать логику принятия решений, систему приоритетов целеполагания отдельного человека на основании узловых категорий и мыслительных цепочек связей между ними (1976).

В прикладной политологии данный метод используется для исследования широкого спектра проблем: процессов принятия решений в сфере государственного управления, для оценки стратегий участников конфоликта, построение карт представителей политической элиты, анализа ценностных «картин мира» лидеров государств в компаративных исследованиях международных процессов и отношений.

Одним из активно развивающихся направлений можно считать исследования ценностных картин, дискурсивных практик и цифровых профилей активных участников сетевых сообществ (Бродовская \& Домбровская, 2020). За последние 20 лет интенсивно развиваются методики и подходы конструирования коллективных когнитивных карт (Wang et al, 2018). В рамках этого направления выделяют две техники: 1) технику агрегирования, которая на первом шаге анализа данных предполагает разработку индивидуальных карт, на втором шаге объединяющихся в единую; и 2) коллективную технику, которая делает акцент на иной стратегии, когда в ходе групповой работы строится одна общая карта.

«В то время как агрегирование обеспечивает комплексное представление по проблемной ситуации с учетом разнообразия индивидуальных представлений о ней, коллективный подход направлен, в первую очередь, на достижение общего понимания в команде по исследуемой проблемной ситуации» (Авдеева \& Коврига, 2014).

В данном исследовании будут приведены результаты коллективных когнитивных карт, построенных с использованием техники агрегирования. 


\section{ПОЛИТИЧЕСКИЙ ВИДЕОБЛОГИНГ В РОССИИ И ПРОТЕСТНОЕ ДВИЖЕНИЕ}

Под лидерами общественного мнения понимаются блогеры, журналисты и другие публичные люди, которые в своей постоянной повестке дня обсуждают, комментируют социально-значимые, общественно важные политические темы.

«В коммуникационном пространстве лидеры мнений “социального типа” выполняют функцию точек кристаллизации, структурирующих информационное пространство. При этом разница их мировоззренческих позиций менее важна, чем само наличие продуманного мировоззрения. Таким образом, социальные блогеры формируют в информационном пространстве некую “кристаллическую решетку”, в узлах которой находятся важные для социума и часто дополняющие друг друга социально-мировоззренческие позиции» (Витвинчук и др., 2017, с. 97).

Они выступают как активные ключевые коммуникаторы, которые интерпретируют и конструируют смыслы политических событий для своего молодежного сегмента аудитории (Абросимова и др., 2017; Сотрудничество, 2018, с. 56). Характер подачи информационных материалов, сочетание различных техник привлечения внимания к акциям протеста, подчеркивание самопозиционирования и самоидентичности в конфоликтных ситуациях позволяет рассматривать их в качестве лидеров общественного мнения (Соловей, 2018), способных существенно влиять на ценностные установки и политические взгляды молодежной части аудитории видеохостинга YouTube (Кирьянова, 2019; Петрова, 2019).

Политический видеоблогинг в России получает развитие с начала 2010-х гг., что можно связать с массовым распространением необходимых информационных технологий (Зигадуллина, 2018). О значительных политических эффектах видеоблогинга можно говорить, вероятно, не ранее середины 2010-гг.; символическим «Рубиконом» можно считать, в частности, события 2017 года (Киселева, 2019). В последующей истории протестного движения, в частности, в акциях 2019-2020 гг. именно видеоблогинг, превосходя другие формы, становится основной и важнейшей формой распространения информации в интернете (Гришин, 2021).

20 видеоблогеров, фигурирующих в нашем исследовании, чрезвычайно разнятся по множеству оснований (табл.1).

В качестве первого критерия сравнения следует назвать совершенно формальный аспект, заключающийся в наличии собственного видеоблога. По данному критерию единственное исключение состав- 
ляет Любовь Соболь - называемая молодежью в числе наиболее известных и популярных видеоблогеров, она не располагает собственным Youtube-каналом, но использует различные блоги, в частности, видеоканал «команды» Алексея Навального «Навальный Live».

\begin{tabular}{|c|c|c|}
\hline Видеоканал Youtube & Год регистрации & $\begin{array}{l}\text { Количество } \\
\text { подписчиков }\end{array}$ \\
\hline $\begin{array}{l}\text { Канал «Команда Жукова» } \\
\text { (ранее - «Блог Жукова») }\end{array}$ & 2015 & 233 тыс. \\
\hline $\begin{array}{l}\text { Канал Алексея Пивоварова } \\
\text { «Редакция» }\end{array}$ & 2018 & 1,9 млн. \\
\hline Канал «Руслан Усачев» & 2010 & 2,5 млн. \\
\hline Канал «Дмитрий Гордон» & 2011 & 1,44 млн. \\
\hline varlamov & 2008 & 2,2 млн. \\
\hline вДудь & 2014 & 8,8 млн. \\
\hline Алексей Навальный & 2013 & 6,42 млн. \\
\hline Константин Сёмин & 2015 & 519 тыс. \\
\hline Илья Яшин & 2013 & 300 тыс. \\
\hline Ксения Собчак & 2017 & 1,9 млн. \\
\hline Yulia Latynina & 2018 & 220 тыс. \\
\hline Артемий Лебедев & 2006 & 550 тыс. \\
\hline Александр Невзоров & 2011 & 1 млн. \\
\hline Parfenon & 2018 & 1 млн. \\
\hline Евгений Ройзман & 2017 & 300 тыс. \\
\hline Романов & 2015 & 375 тыс. \\
\hline Михаил Ходорковский & 2009 & 850 тыс. \\
\hline Максим Шевченко & 2017 & 760 тыс. \\
\hline Екатерина Шульман & 2016 & 435 тыс. \\
\hline
\end{tabular}

Таблица 1. Информация об Youtube-каналах популярных у российской молодежи видеоблогеров, освещавших протестные акции в 2019-2020 гг. 
У 19 других лидеров собственные видеоканалы присутствуют, однако, степень их зависимости от собственного канала следует признать разной. В частности, для Александра Невзорова или Екатерины Шульман их персональные видеоканалы не являются главными средствами обеспечения их присутствия в медийном пространстве. Напротив, у таких персон, как Юрий Дудь или Алексей Романов их персональные видеоканалы являются основными средствами, обеспечивающими их влияние в интернете (Зубанова \& Зыховская, 2018)

Рассматриваемые в нашем исследовании 20 видеоблогеров также чрезвычайно разнятся по степени зависимости от интернета в целом. Влияние некоторых из них (Ю. Дудь, И. Варламов, А. Романов) практически полностью основано на присутствии в интернете. Напротив, влияние таких фигур, как Е. Шульман, К. Собчак или К. Семин, основывается на использовании не только интернета, но и других средств, в том числе традиционных СМИ. Для данных лидеров общественного мнения представляется важным, но и методологически сложным разделить степень их влияния на аудиторию именно в качестве видеоблогеров и в качестве популярных лиц, использующих для распространения информации, среди прочих, и средства интернета.

Рассматриваемые блогеры различаются в зависимости от того, насколько важную роль сыграл видеоблогинг в превращении их во влиятельных медийных персон. Большинство из 20 блогеров приобретением популярности обязаны иным средствам информации, в том числе традиционным СМИ. В частности, такие лидеры, как Л. Парфенов или К. Собчак, перенесли свою активность в интернет, уже будучи популярными фигурами. Отдельно стоит выделить группу лидеров, которые изначально добились популярности благодаря интернету. Но и у этой группы присутствует внутренняя дифференциация: А. Романов представляет редкий случай, когда лидер общественного мнения изначально добился популярности на основе видеоблогинга; в то время как А. Навальный или И. Варламов приобрели популярность и влиятельный статус на основе других интернетплатформ, в первую очередь - благодаря livejournal. Таким образом, абсолютное большинство из отобранной нами группы популярных в молодёжной среде видеоблогеров добились влиятельного статуса на основе использованиях иных информационных площадок.

Самыми старыми видеоблогами располагают А. Лебедев и И. Варламов (их видеоканалы в YouTube зарегистрированы соответственно в 2006 и 2008 гг.). Самый молодой блог принадлежит Л. Парфенову (канал "Parfenon" зарегистрирован в 2018 г.). 
По количеству подписчиков лидирует видеоканал Юрия Дудя (8,8 млн. подписчиков). Самая скромная аудитория подписчиков у анала Юлии Латыниной - 221 тыс. человек.

\section{РЕЗУЛЬТАТЫ КОГНИТИВНОГО КАРТИРОВАНИЯ}

Одной из эмпирических задач исследования, проводимого в рамках проекта, было выявление ценностных установок, приоритетов, индивидуальных логических цепочек лидеров общественного мнения русскоязычного сегмента видеохостинга YouTube, которые комментировали или делали обзоры акций протестов, проходивших в крупных городах в 2019-2020 гг. Исследование контента блогов основывалось на нескольких параметрах:

1) соотношение доли сообщений/обзоров, репрезентирующих различные аспекты темы акций протеста;

2) тип логических цепочек/конструктов;

3) сила и характер логических связей между событиями и акторами;

4) применяемые схемы освещения протестной активности.

Выборка исследования строилась по 2 ступенчатой модели. На первом уровне осуществлялся отбор оппозиционно настроенных лидеров общественного мнения YouTube для русскоязычного сегмента молодых людей в возрасте 18-36 лет. Критериями отбора выступали объем аудитории (количество подписчиков, просмотров и комментариев) и тематика обзоров/комментариев данными персонами политических и социально-политических событий новостной повестки дня. В итоге объем выборки составил 20 персон, которые методом «первого встречного» попали в выборочную совокупность по указанным критериям.

На втором уровне осуществлялся отбор информационных материалов, видео обзоров протестных акций по выбранным кейсам. Сетевой подход в сочетании с методом картирования позволил выявить причинно-следственные связи между приоритетными смысловыми категориями, оценить логичность и последовательность системы аргументации выбранных лидеров.

«Методологические принципы когнитивного подхода позволяют проанализировать процессы формирования субъективной социальной реальности, субъективного восприятия и интерпретации сообщений, транслируемых в пространстве социальных медиа» (Бродовская и др., 2018, c. 53). 
В выборку методом основного массива были включены все видео/обзоры или иные материалы по выбранным кейсам. На первом этапе анализа для каждого лидера общественного мнения было построено несколько когнитивных карт. На втором этапе для каждого кейса была построена коллективная когнитивная карта методом агрегирования.

Первым кейсом были события в Екатеринбурге в 2019 году. Все выбранные инфлюенсеры освещали, с той или иной степенью осведомленности, ход гражданского противостояния по вопросу постройки храма на территории сквера. Сравнительный анализ всех карт позволил выделить общие логические, структурные компоненты контента. Можно выделить несколько логических блоков.

Первый блок связан с позиционированием участников акций протеста. Они характеризуются через категории «активные люди», «люди с гражданской позицией», «ответственные и небезразличные граждане». Особый акцент авторами контента делается на конструировании положительного образа протестующих, апеллируя как к рациональным, так и к эмоциональным аргументам. Рациональная аргументация блогеров строиться на базовых установках демократического общества, таких как уважение прав граждан, ценности и мнения простых людей. С одной стороны, эти идеи демонстрируют либерально-демократические ценностные ориентиры, которые разделяют многие представители молодого поколения. С другой стороны, авторы четко разделяют всех участников конфоликта на две стороны по упрощенной схеме черно-белого восприятия ситуации. Таким образом подчеркивается отличительная особенность участников акций протеста и демонстрируется модель поведения, которая позволяет выделиться из общей массы обывателей и самоидентифицироваться. Одновременно с этим, эмоциональный компонент аргументации связывает конструируемый образ, с такими положительными характеристиками как смелость, независимость, самостоятельность. Совокупность выявленных факторов способствует конструированию положительного, привлекательного для молодежи, образа борца.

Анализ логических связей выявил, что выход людей на улицы авторы контента связывают с двумя основными категориями. Первая категория - «ошибки региональной власти», которые рассматриваются как базовая причина конфликтной ситуации. Вторая «действия силовых структур». Наибольшее количество и сила связей наблюдается между категориями «протестующие» и «действия силовых структур». Необходимо отметить отрицательный характер 
связи между этими двумя категориями и в 90\% случаев негативное влияние силовых структур направлено на участников акций протеста.

Второй логический блок - статус и характер действий представителей силовых ведомств в гражданском конфликте. Эта категория очень значима по количеству связей с другими категориями. Инфлюенсеры очень подробно освещают действия полиции и представителей ОМОНа. Основной проблемой они считают применение мер силового воздействия на рядовых граждан и многочисленные задержания, которые носят незаконный характер.

Смысловые цепочки этого блока выявили противоречие в контенте блогеров. С одной стороны, лидеры общественного мнения подчеркивают незаконность задержаний, арестов и других мер воздействия на протестующих. Силовые ведомства представляются как инструмент власти, применение которого демонстрирует слабость и страх власти перед силой протеста. С другой, не приводятся какиелибо конкретные случаи применения насилия со стороны полиции, нет случаев жестокого обращения с задержанными. Можно сделать вывод, что силовой ресурс властью не используется в полную силу, а ограничивается определенным набором мер воздействия. Фактическое отсутствие жесткого подавления акций протеста со стороны региональной власти можно трактовать двояко, либо как действия, демонстрирующие страх, либо как рациональную и сдержанную позицию на стадии острого конфоликта. В материалах данного кейса блогеры не сформировали однозначной трактовки позиции власти.

Третий логический блок характеризует причины и последствия акций протеста. В качестве основной причины протеста выступает отсутствие диалога между властями города и жителями. Четко декларируется, что отсутствие каналов и площадок для коммуникации, а также нежелание публично обсуждать проект и договариваться, провоцируют людей выходить на улицы, чтобы быть услышанными. Отсутствие демократических институциональных механизмов разрешения конфликтных ситуаций обозначается в качестве главной проблемы современной российской системы власти. Таким образом, авторы контента подчеркивают роль власти как активного субъекта противостояния, но позиционируют его как «виновника-причины конфиликта».

Четвертыц̆ блок - ценностные и эмоциональные мотиваторы. Участие людей в акциях протеста связывается с набором демократических и постдемократических ценностных установок. Обзоры и комментарии выстраиваются таким образом, что обоснованность протестных акций объясняется не столько рациональным и логически 
взвешенным решением протестующих обозначить свою позицию/ несогласие перед властью, сколько эмоциональным и идеализированным восприятием демократических практик, которые существуют в странах Европы и США.

Логика построения смысловых цепочек выбранных комментаторов/блогеров предполагает четкое разделение на два лагеря: «мы протестующие, жители города и солидарные с ними, которых не уважают и с чьим мнением не считаются» - противники стройки; и «они - власть, губернатор, Путин, спонсоры, полиция» - все те, кто «за» постройку Храма на месте сквера. Происходит жесткая поляризация сторон спора. Невозможность решения спорной ситуации в рамках демократических практик и институтов лидеры общественного мнения обосновывают существующей системой органов власти и принципами ее организации.

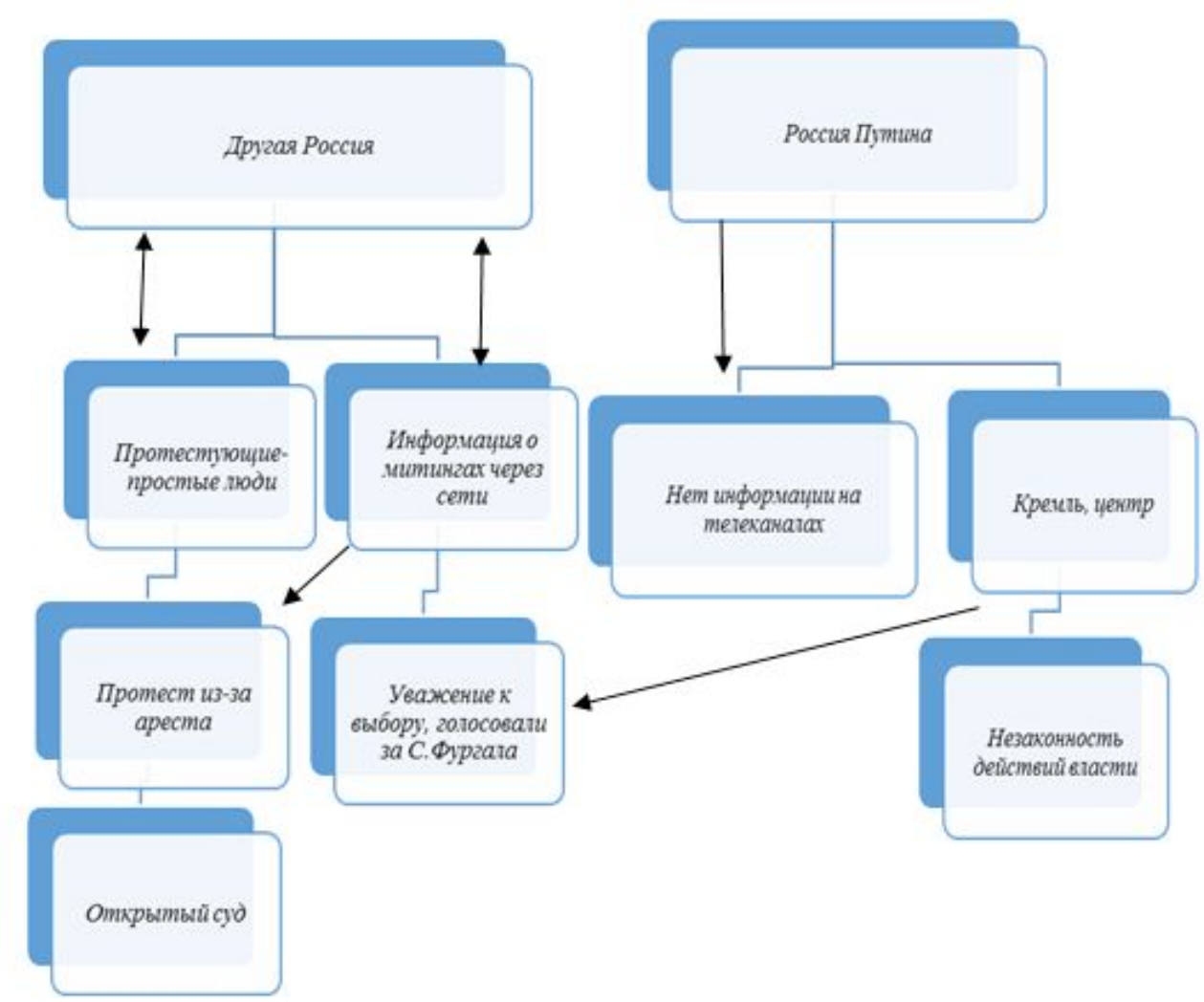

Рисунок 1. Когнитивная карта освещения протестных акций в Екатеринбурге в 2019 г.

Вторым кейсом стали акции протеста лета - начала осени 2019 года в Москве связанные с выборами в МосГорДуму. Поводом к началу акций протеста стал отказ в регистрации оппозиционных кандидатов. Агрегирование всех карт позволило выделить наиболее значимые 
структурные компоненты контента, которые можно разделить на несколько логических блоков.

Первыцй блок, как и в первом кейсе, характеризует участников протестных акций через категории «искренние люди», «нас много и мы не меньшинство», «люди, которые борются за свои права». Таким образом создается представление о значимости событий и важности участия в них. Этот способ позиционирования участников протестных акций содержит в себе двойную мотивационную компоненту. С одной стороны, категория «искренние люди» предполагает морально-этическую оправданность действий всех людей, которые вышли на улицы Москвы. С другой, подразумевается естественный, не искусственный, несрежиссированный характер протестной активности.

Это важный момент для консолидации поддержки/сочувствия или участия в протестных акциях. Категория «мы - не меньшинство» выполняет значимую символическую роль, т.к. апеллирует к чувству сопричастности с большими социальными группами, что позволяет ощущать силу и историческую роль событий. Используемые приемы конструирования образа протестующих сокращают дистанцию между реципиентами контента и участниками событий, что усиливает влияние на аудиторию.

В данном блоке можно выделить также категории «уважение права выбора» и «уважение мнения простых людей», которые логически связаны со вторым блоком.

В рамках второго блока основной акцент делается на незарегистрированных кандидатах, которые олицетворяют собой единство оппозиционных сил. Они позиционируются как представители демократических сил современной России и четко противопоставляются мэру Москвы С. Собянину, бюрократам-чиновникам. Эмоциональный компонент связывает конструируемый образ кандидатов, как «жертвы беззакония», с такими характеристиками как смелость, современность, борьба. В цепочках всех инфиюенсеров сохраняется жесткое символическое разделение всех участников событий на две стороны конфликта. Одна сторона представлена протестующими москвичами и незарегистрированными кандидатами. Эти субъекты протеста тесно связаны между собой через категории «требование представительства своих кандидатов», «право на выбор», «борьба за свободу», «мы поколение без страха», «новая, молодая Россия».

По аналогии с кейсом Екатеринбурга, эти идеи демонстрируют либерально-демократические политические взгляды, но в тоже время, авторы включают в контекст события межпоколенческий аспект 
противостояния. Логика построения смысловых цепочек выбранных комментаторов/блогеров демонстрирует призыв к мобилизации, на основе создания символического противопоставления между «здоровой Россией будущего» и «старой, больной Россией в лице Путина, Собянина и др».

Третий блок характеризует вторую сторону конфиликта, которая представлена двумя акторами. Первый субъект - политическая власть - раскрывается через смысловые категории «власть», «Кремль», «партия Единая Россия», мэр С. Собянин. Каждый из элементов характеризует единовластие политической и административной системы властной вертикали. Второй субъект это силовые структуры (силовики, $\mathrm{OMOH}$, полиция) функция которых давление на участников протестных акций. Слабость, неспособность и нежелание первого субъекта решать спорные ситуации с помощью легальных, демократических норм, по мнению блогеров,обуславливают необходимость выхода на улицу как последнего и единственного действенного аргумента. Аресты, задержания, перекрытие и блокирование улиц - способы подавить, а не решить конфликт. В качестве ответственного лица за новый виток уровня напряженности называются власти, которые приняли решение отказать в регистрации кандидатам не от партии Единая Россия.

Таким образом, конфликт из предвыборного переводится на другой уровень. Он представляется как противостояние не только с чиновниками из избирательной комиссии, но со всей недемократической системой власти.

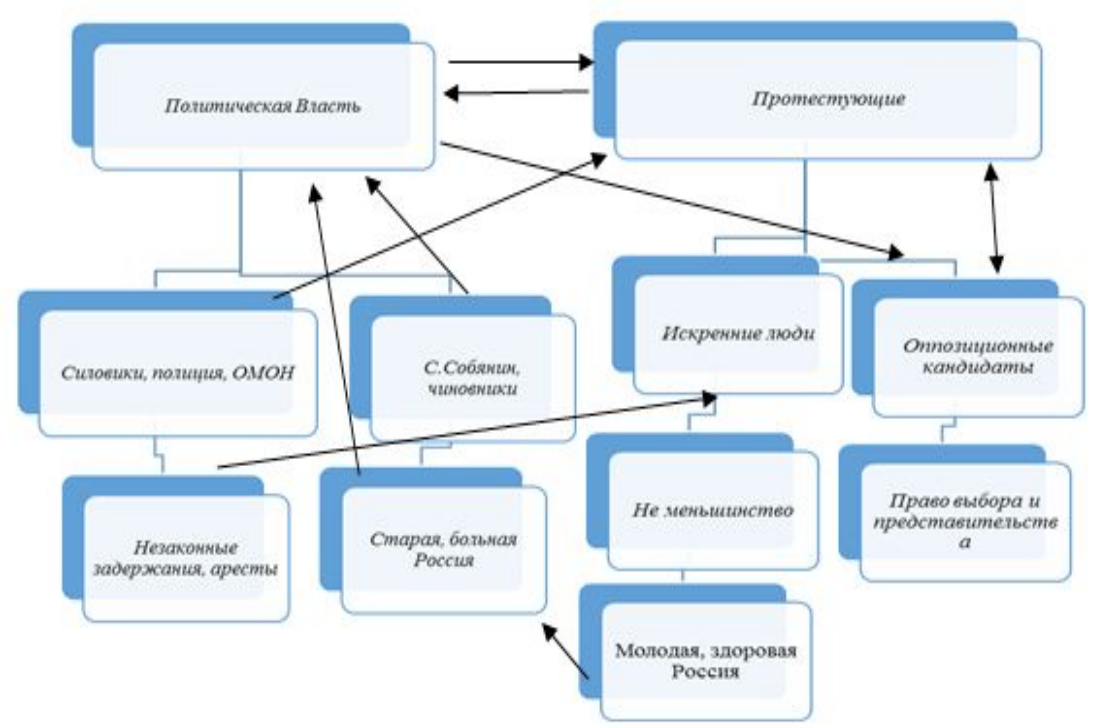

Рисунок 2. Когнитивная карта освещения протестных акций в связи с выборами в Мосгордуму в 2019 г. 
В качестве третьего кейса представлен анализ освещения и комментирования лидерами общественного мнения акций протеста, проходивших в Хабаровске летом 2020 года. Формальным поводом для массовых митингов стал арест, действующего на тот момент губернатора Хабаровского края С. Фургала. Событие регионального масштаба стало серьезным информационным поводом в интернете. Агрегирование всех когнитивных карт позволило выделить два смысловых блока и определить их как наиболее значимые акторы.

Первый блок категорий обозначает протестующих как людей, которые выступили против Кремля и его незаконных действий. Второй блок категорий характеризует федеральный центр как субъекта данного конфликта.

Это важный момент позиционирования участников протеста. Комментаторы и инфлюенсеры, которые делали обзоры, четко обозначают две стороны очередного публичного политического противостояния. С одной стороны конфликта жители Хабаровского края, которых возмутил арест С. Фургала, избранного на последних губернаторских выборах от партии ЛДПР. Первый актор раскрывается через категорию «простые, обычные люди», которые сделали свой выбор в день голосования. Создание положительного образа протестующих происходит с использованием рациональных и эмоциональных компонентов. Акцент делается «на уважении выбора и мнения простых людей». С другой стороны Кремль, федеральный центр как сосредоточение далекой и надоевшей власти. Важно отметить, что оба субъекта позиционируются как два мира. Один мир - Россия, представленная на федеральных телеканалах, которые не освещают события, происходящие в Хабаровском крае: Россия Путина с подконтрольными СМИ и «в этой стране ничего не происходит». Но есть другая Россия, в которой люди недовольны действиями федеральной власти и готовы выразить свой протест на улице. Другая Россия - «современная, информационная, неподчиняющаяся Кремлю», которая требует «информации и открытого суда» над С. Фургалом.

Акции протеста подробно освещались почти всеми инфюенсерами и рассматривались ими как региональный протест против власти Москвы. Анализ логических связей между категориями показал, что, по мнению лидеров общественного мнения, выход людей на улицы связан с двумя основными причинами. Первая - вмешательство Москвы во внутреннюю политику региона, вторая - незаконный арест. Первая причина обозначает внутриэлитный конфоликт между центром и региональной элитой. Вторая - артикулируется как проблема легитимности и доверия к центральной власти. Протесту- 
ющие требовали открытого судебного процесса над своим губернатором, который для них является лидером протестного голосования. Основным мотивом ареста называют не реальные преступления С. Фургала, а месть со стороны федерального центра за то, что кандидат от партии Единая Россия не стал победителем на выборах.

В качестве одного из важных катализаторов протеста во всех материалах блогеров выступает «тактика молчания» в публичном дискурсе о конфликте, отсутствие диалога между федеральной властью и избирателями. Основный акцент делается на внутриполитической борьбе между разными элитными группами. Но отличительной особенностью этих митингов можно назвать не только широкий географический охват, но и отсутствие в течение долгого времени насильственных действий со стороны региональной власти по отношению к протестующим. В этом кейсе власть представляется пассивной стороной конфликта, которая выбрала тактику игнорирования в публичном пространстве самого факта митингов.

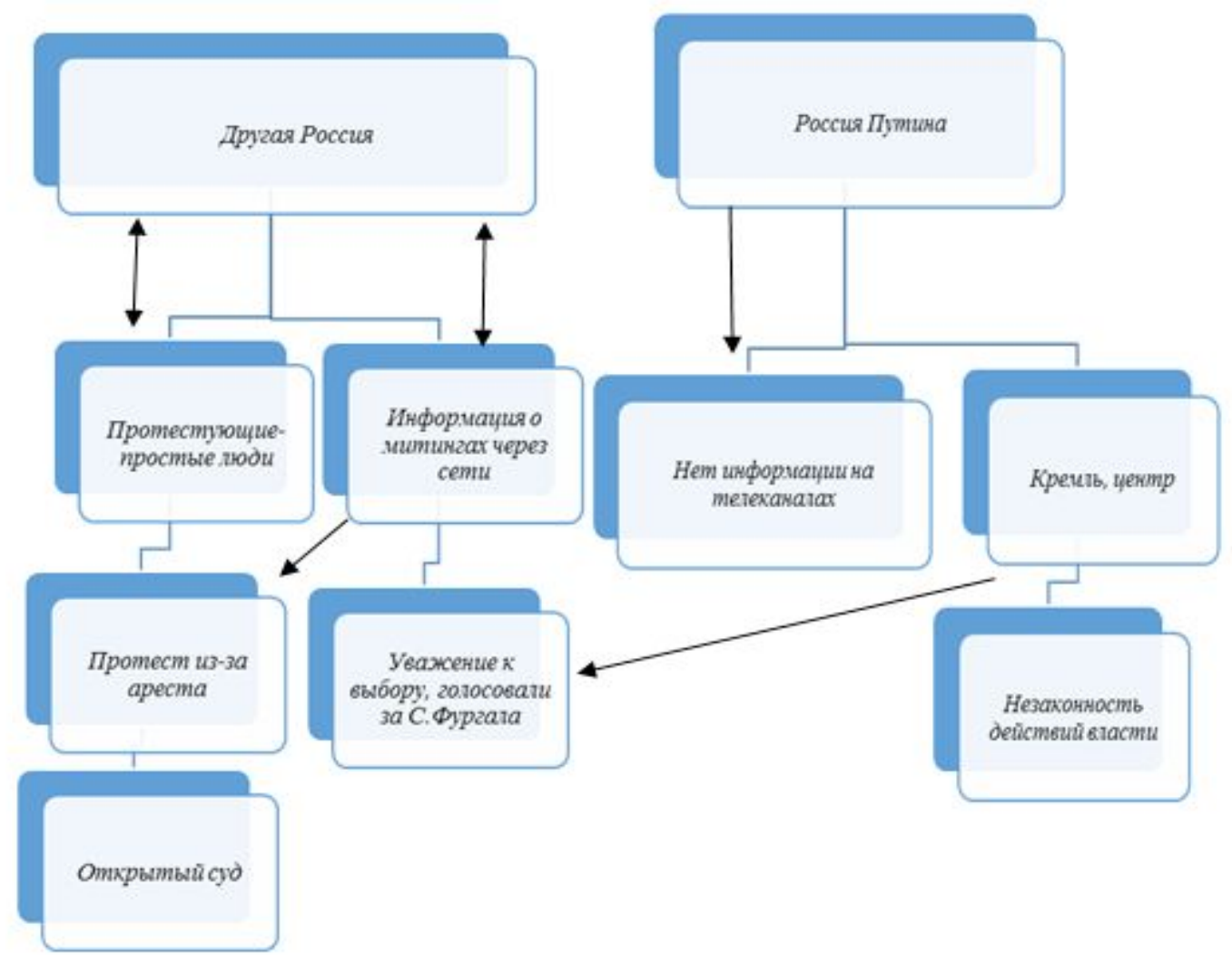

Рисунок 3. Когнитивная карта освещения протестных акций в Хабаровске в 2020 г. 


\section{ВЫВОДЫ}

В рамках проведенного исследования метод когнитивного картирования позволил проанализировать восприятие и интерпретацию лидерами общественного мнения, которые оппозиционно настроены по отношению к власти, акций протеста, проходивших в Екатеринбурге, Москве, Санкт-Петербурге, Хабаровске 2019-2020 гг.. События в Екатеринбурге и Хабаровске являются примерами региональных кейсов, которые стали значимыми информационными поводами для того, чтобы привлечь внимание молодых людей всей страны к этим событиям.

Проведенное исследование не может помочь в оценке эффективности мобилизующего воздействия российских видеоблогеров, но представляет значимость для изучения особенностей их мобилизующих усилий.

Результаты когнитивного картирования раскрывают ценностную систему популярных среди молодежи интерпретаторов политических событий. Представленные когнитивные карты позволяют сделать вывод, что практически у всех рассмотренных нами лидеров общественного мнения присутствует единая ценностная картина в оценке протестных событий. Также для них характерна единая позиция в отношении целесообразности участия в протестной деятельности.

Основной акцент молодежными блогерами делается на то, что протестующие - это обычные люди, которых оскорбили, и чье мнение проигнорировали. Этот стилистический прием сокращает дистанцию между реципиентами информации и непосредственными участниками событий, что позволяет конструировать консолидированное символическое пространство смысла.

Подчеркивается важность права выбора этих людей, т.е. акцентируется внимание на правах, которые гарантируются Конституцией и другими нормативными актами. Конструирование положительного образа протестующих происходит с опорой на рациональные, демократические требования. Такой посыл априори предполагает, что власть нарушает базовые принципы современного демократического государства и выступает в качестве виновника происходящих событий.

Отсутствие демократических институциональных механизмов разрешения конфликтных ситуаций обозначается в качества главной проблемы современной власти. Внимание аудитории акцентируется на существующих системных недостатках политического процесса, которые невозможно устранить в короткие сроки. Как следствие сохраняется благоприятная почва для поляризации мнений и дальнейшего 
использования митингов как инструмента влияния на конкретные политические решения.

Включение в конфликтное поле межпоколенческого фактора актуализирует проблему акций протеста в сознании молодежной аудитории.

Выделенные аспекты особенно важны, т.к. инфлюенсеры, которые обладают достаточным авторитетом и социальным капиталом для влияния на широкую аудиторию в сети, выступают в качестве активных субъектов политической коммуникации (Попова \& Лагутин, 2019). В условиях, когда значительную часть их постоянной аудитории составляют люди молодого поколения, они выполняют функцию агентов политической социализации и основных ретрансляторов неофициального либерально-демократического дискурса.

Не смотря на то, что вопрос о применимости теории мобилизации к деятельности оппозиционно настроенных видеоблогеров не является в полной мере ясным, представленная в данном исследовании картина может восполнить представления о мотивах и ориентирах представителей молодежи, участвующих в протестном движении в современной России.

\section{БЛАГОДАРНОСТИ}

Исследование выполнено при финансовой поддержке РФФИ и ЭИСИ в рамках научного проекта №20-011-31753 «Молодежь мегаполисов как социальная основа публичного протеста: предпосылки, технологии, формы, риски и эффекты политической онлайн-мобилизации»

\section{Список литературы}

Abelson, R. (1979). Differences Between Belief and Knowledge Systems. Cognitive Science, 3, 355-366.

Axelrod, R. (Ed.). (1976). Structure of Decision: The Cognitive Maps of Political Elites. Princeton: Princeton University Press.

Gray, S. A., Gray, S., De Kok, J. L., Helfgott, A. E. R., O’Dwyer, B., Jordan, R., \& Nyaki, A. (2015). Using fuzzy cognitive mapping as a participatory approach to analyze change, preferred states, and perceived resilience of social-ecological systems. Eco$\log y$ and Society, 20(2). doi: 10.5751/es-07 396-200 211

Karlsen, R. (2015). Followers are opinion leaders: The role of people in the flow of political communication on and beyond social networking sites. European fournal of Communication, 30(3), 301-318. doi: 10.1177/0 267323115577305 
Leites, N. (1951). The Operational Code of the Politburo. New York: McGraw-Hill Book Company.

Olazabal, M., Neumann, M. B., Foudi, S., \& Chiabai, A. (2018). Transparency and Reproducibility in Participatory Systems Modelling: The Case of Fuzzy Cognitive Mapping. Systems Research and Behavioral Science, 35(6), 791-810. doi: 10.1002/sres.2519

Wang, M., Wu, B., Kirschner, P. A., \& Michael Spector, J. (2018). Using cognitive mapping to foster deeper learning with complex problems in a computer-based environment. Computers in Human Behavior, 87, 450-458. doi: 10.1016/j.chb.2018.01.024

Авдеева, 3. К., \& Коврига, С. В. (2014). О некоторых принципах и подходах к построению коллективных когнитивных карт ситуаций. Управление Большими Системами: Сборник Трудов, (52), 37-68.

Бродовская, Е. В., \& Домбровская, А. Ю. (2020). Социальная база Информационного потока внешнего давления в новых медиа Крыма и Севастополя. Власть, 28(4), 84-92. doi: 10.31171/vlast.v28i4.7439

Бродовская, Е. В., Домбровская, А. Ю., Пырма, Р. В., \& Карзубов, Д. Н. (2018). Украинские социально-медийные потоки о Крыме: Результаты когнитивного картирования украинских блогов и каналов новых медиа. Известия Тульского государственного университета. Гуманитарные науки, (4), 51-61.

Витвинчук, В. В., Фотиева, И. В., Семилет, Т. А., \& Лукашевич, Е. В. (2017). Проблема лидеров мнений в публичной коммуникации. Сибирский философский журнал, 15(4), 91-101. doi: 10.25205/2541-7517-2017-15-4-91-101

Гришин, Н. В. (2021). Теория подкрепления» и изучение влияния интернет-технологий на политическое участие современной молодежи. Вестник Российского университета дружбы народов. Серия: Политология, 23(1), 47-59. doi: 10.22363/2313-1438-2021-23-1-47-59

Гришин, Н. В., \& Линдерс, А. М. Р. (2020). Децентрализация системы управления выборами. Полития: Анализ. Хроника. Прогноз (Журнал политической философии и социологии политики), (3), 99-115. doi: 10.30570/2078-5089-2020-98-3-99-115

Зигадуллина, А. Р. (2018). Преодоление парасоциальности: Лидеры YouTube как генераторы гражданской журналистики (на примере каналов sobolev и Philip DeFranco). Знак: Проблемное Поле Медиаобразования, (2), 17-22.

Зубанова, Л. Б., \& Зыховская, Н. Л. (2018). Сетевые проекты: Потенциал воздействия на аудиторию (на примере проекта «вДудь»). Знак: проблемное поле медиаобразования, (4), 119-127.

Кирьянова, С. (2019). Блогер или журналист-Почему подростки так ценят мнение ютуберов. Извлечено от https://www.tulapressa.ru/2019/06/bloger-ili-zhurnalistpochemu-podrostki-tak-cenyat-mnenie-yutuberov-5302/

Киселева, А. (2019). Оценка воздействия социальных медиа на политические и социокультурные взгляды молодежи в условиях глобальной трансформации общества (на примере видеоблогинга). Векторы благополучия: экономика и социум, (1), 26-36. 
Лагутин, О. В., \& Шентякова, А. В. (2018). Эмпирическое измерение социального капитала молодежи современного мегаполиса. Политическое пространство и соииальное время: Синергия смыслов и ценностей. Сборник научных трудов XXXIV Международного Харакского форума. Под редакиией Т.А. Сенюшкиной, 95-100. Ялта: Общество с ограниченной ответственностью «Издательство Типография «Ариал».

Морозова, А. А. (2018). Видеоблоги для молодежной аудитории: Социологический портер зрителя. Челябинский гуманитарий, (4), 20-26.

Петрова, М. В. (2019). Тактики речевой контрманипуляции в российских политических видеоблогах. Вопросы теории и практики журналистики, 8(3), 625-639. doi: 10.17150/2308-6203.2019.8(3).625-639

Попова, О. В. (2009). Измерительный инструмент» в сравнительной политологии: К вопросу о нерешенных проблемах. Политическая экспертиза. ПОЛИТЭКС, 5(1), 271-291.

Попова, О. В., \& Лагутин, О. В. (2019). Политические настроения молодежи: Лояльность или протест? Вестник Российского университета дружбы народов. Серия: Политология, 21(4), 599-619. doi: 10.22363/2313-1438-2019-21-4-599-619

Роменков, А. В. (2008). Интернет-блог как инструмент политической борьбы. Власть, (7), 79-83.

Сморгунов, Л. В. (Ред.). (2018). Сотрудничество в публичной политике и управлении. Санкт-Петербург: Издательство Санкт-Петербургского университета.

Соколов, А. В., \& Палагичева, А. В. (2020). Мобилизация и демобилизация в сетевом политическом протесте. Политическая наука, (3), 266-297. doi: 10.31249/poln/ 2020.03.12

Соловей, В. Д. (2018). Особенности политической пропаганды в цифровой среде. $Г у$ манитарные науки. Вестник Финансового университета, 8(1), 81-87. doi: 10.26794/2226-7867-2018-7-1-81-87

Филипова, А. Г., Ардальянова, А. Ю., \& Абросимова, Е. Е. (2017). Видеоблогинг и современные подростки: Опасности интернет-пространства. Теория и практика общественного развития, (8), 9-13. doi: 10.24158/tipor.2017.8.1

Шарапов, Р. И. (2017). Условия политической мобилизации в сети Интернет. Социодинамика, (10), 1-8. doi: 10.25136/2409-7144.2017.10.22073

\section{References}

Abelson, R. (1979). Differences Between Belief and Knowledge Systems. Cognitive Science, 3, 355-366.

Avdeeva, Z. K., \& Kovriga, S. V. (2014). On some principles and approaches to building collective maps of the situation. Big Systems Management: A Collection of Works, (52), 37-68. (In Russian). 
Axelrod, R. (Ed.). (1976). Structure of Decision: The Cognitive Maps of Political Elites. Princeton: Princeton University Press.

Brodovskaya, E. V., \& Dombrovskaya, A. Yu. (2020). Social base of the Information flow of external pressure in the new media of Crimea and Sevastopol. Power, 28(4), 84-92. doi: 10.31171/vlast.v28i4.7439 (In Russian).

Brodovskaya, E. V., Dombrovskaya, A. Yu., Pyrma, R. V., \& Karzubov, D. N. (2018). Ukrainian social media streams about Crimea: results of cognitive mapping of Ukrainian blogs and new media channels. Bulletin of the Tula State University. Humanities, (4), 51-61. (In Russian).

Filipova, A. G., Ardalyanova, A. Yu., \& Abrosimova, E. E. (2017). Video blogging and modern adolescents: the dangers of the Internet space. Theory and practice of social development, (8), 9-13. doi: 10.24158/tipor.2017.8.1 (In Russian).

Gray, S. A., Gray, S., De Kok, J. L., Helfgott, A. E. R., O’Dwyer, B., Jordan, R., \& Nyaki, A. (2015). Using fuzzy cognitive mapping as a participatory approach to analyze change, preferred states, and perceived resilience of social-ecological systems. Ecology and Society, 20(2). doi: 10.5751/es-07 396-200 211

Grishin, N. (2021). Reinforcement Theory and Study of the Impact of Internet Technologies on Political Participation of Modern Youth. RUDN Journal of Political Science, 23(1), 47-59. doi: 10.22363/2313-1438-2021-23-1-47-59 (In Russian).

Grishin, N., \& Leenders, A. M. R. (2020). Decentralization of Electoral Governance. Politeiajournal of Political Theory Political Philosophy and Sociology of Politics, (3), 99-115. doi: 10.30570/2078-5089-2020-98-3-99-115 (In Russian).

Karlsen, R. (2015). Followers are opinion leaders: The role of people in the flow of political communication on and beyond social networking sites. European fournal of Communication, 30(3), 301-318. doi: 10.1177/0 267323115577305

Kiryanova, S. (2019). Blogger or journalist - why do teens value the opinion of YouTubers so much. Retrieved from https:/www.tulapressa.ru/2019/06/bloger-ili-zhurnalist-pochemu-podrostki-tak-cenyat-mnenie-yutuberov-5302/ (In Russian).

Kiseleva, A. (2019). Assessment of the impact of social media on the political and sociocultural views of young people in the context of the global transformation of society (on the example of video blogging). Well-being vectors: economy and society, (1), 2636. (In Russian).

Lagutin, O. V., \& Shetyakova, A. V. (2018). Empirical measurement of the social capital of young people in a modern metropolis. Political space and social time: Synergy of meanings and values (edited by T.A. Senyushkina), 95-100. Yalta: Limited Liability Company "Publishing House Typography "Arial". (In Russian).

Leites, N. (1951). The Operational Code of the Politburo. New York: McGraw-Hill Book Company.

Morozova, A. A. (2018). Video blogs for a youth audience: a sociological porter of the viewer. Chelyabinsk Humanities, (4), 20-26. (In Russian). 
Olazabal, M., Neumann, M. B., Foudi, S., \& Chiabai, A. (2018). Transparency and Reproducibility in Participatory Systems Modelling: The Case of Fuzzy Cognitive Mapping. Systems Research and Behavioral Science, 35(6), 791-810. doi: 10.1002/sres.2519

Petrova, M. V. (2019). Tactics of speech counter-manipulation in Russian political video blogs. Questions of theory and practice of journalism, 8(3), 625-639. doi: 10.17150/2308-6203.2019.8(3).625-639 (In Russian).

Popova, O. V., (2009). A "Measuring Tool” in Comparative Political Science: Toward a Question of Unresolved Issues. Political expertise. POLITEX, 5(1), 271-291. (In Russian).

Popova, O. V., \& Lagutin, O. V. (2019). Political Sentiments of Youth: Loyalty or Protest? RUDN Journal of Political Science, 21(4), 599-619. doi: 10.22363/2313-1438-2019-21-4599-619 (In Russian).

Romenkov, A. V. (2008). Internet blog as an instrument of political struggle. Power, (7), 7983. (In Russian).

Sharapov, R. I. (2017). Conditions for political mobilization on the Internet. Sociodynamics, (10), 1-8. doi: 10.25136/2409-7144.2017.10.22073 (In Russian).

Smorgunov, L. V. (Ed.). (2018). Cooperation in public policy and governance. St. Petersburg: St. Petersburg University Press. (In Russian).

Sokolov, A. V., \& Palagicheva, A. V.(2020). Mobilization and demobilization in a networked political protest. Political Science, (3), 266-297. doi: 10.31249/poln/2020.03.12 (In Russian).

Solovey, V. D. (2018). Features of political propaganda in the digital environment. Humanitarian sciences. Financial University Bulletin, 8(1), 81-87. doi: 10.26794/2226-78672018-7-1-81-87 (In Russian).

Vitvinchuk, V. V., Fotieva, I. V., Semilet, T. A., \& Lukashevich, E. V. (2017). The problem of opinion leaders in public communication. Siberian Philosophical fournal, 15(4), 91101. doi: 10.25205/2541-7517-2017-15-4-91-101 (In Russian).

Wang, M., Wu, B., Kirschner, P. A., \& Michael Spector, J. (2018). Using cognitive mapping to foster deeper learning with complex problems in a computer-based environment. Computers in Human Behavior, 87, 450-458. doi: 10.1016/j.chb.2018.01.024

Zigadullina, A. R. (2018). Overcoming Parasociality: YouTube Leaders as Generators of Citizen Journalism (Case Study of the Sobolev and Philip DeFranco Channels). Sign: problematic field of media education, (2), 17-22. (In Russian).

Zubanova, L. B., \& Zykhovskaya, N. L. (2018). Network projects: potential impact on the audience (for example, the "vDud" project). Sign: problematic field of media education, (4), 119-127. (In Russian). 